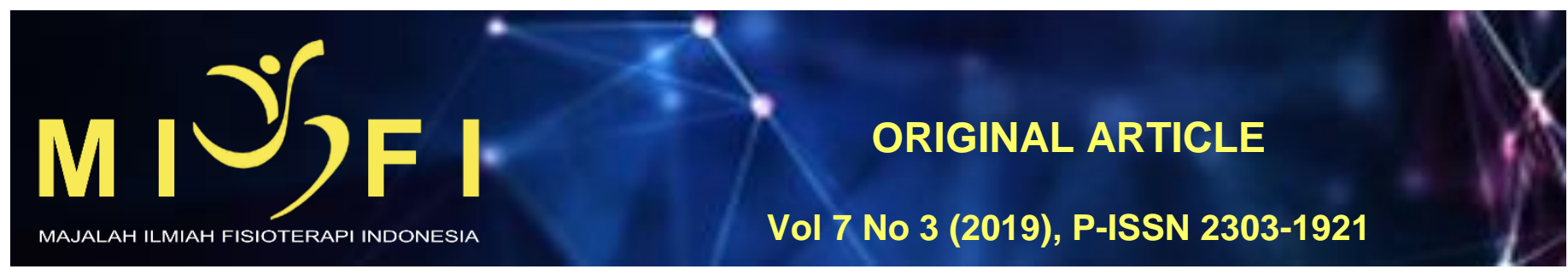

\author{
KOMBINASI FOAM ROLLER DAN CONTRACT RELAX STRETCHING \\ LEBIH BAIK MENINGKATKAN FLEKSIBILITAS HAMSTRING \\ DIBANDING DENGAN CONTRACT RELAX STRETCHING SAJA \\ PADA PEMAIN SEPAK BOLA DI FAKULTAS KEDOKTERAN UNIVERSITAS UDAYANA
}

\author{
Komang Tri Yudartha Widnyana ${ }^{1}$, Indira Vidiari Juhanna ${ }^{2}$, Luh Made Indah Sri Handari Adiputra ${ }^{3}$ \\ ${ }^{1}$ Program Studi Sarjana Fisioterapi dan Profesi Fisioterapi Fakultas Kedokteran, Universitas Udayana \\ ${ }^{2}$ Departemen Fisioterapi, Fakultas Kedokteran, Universitas Udayana \\ ${ }^{3}$ Departemen Fisiologi, Fakultas Kedokteran, Universitas Udayana \\ triyudartha@gmail.com
}

\begin{abstract}
ABSTRAK
Fleksibilitas otot Hamstring merupakan komponen penting karena dapat memperkecil risiko terjadinya cedera pada pemain sepak bola mengingat kasus cedera Hamstring cukup tinggi terjadi pada permainan sepak bola. Guna penelitian ini membuktikan kombinasi Foam Roller dan Contract Relax Stretching lebih baik dibanding pemberian Contract Relax Stretching saja untuk mendapat otot Hamstring yang lebih fleksibel pada pemain sepak bola. Metode Prospektif Pre-Post Test Design digunakan di penelitian ini. Tiap kelompok berjumlah 11 orang dengan cara Simple Random Sampling pada bulan April-Mei 2018 di Laboratorium Fisioterapi FK Unud. Hasil Paired T-Test Kelompok I didapat $p$ sebesar 0,000 dan Kelompok II juga sebesar 0,000 sehingga peningkatan fleksibilitas Hamstring sangat signifikan pada setiap kelompok. Independent T-Test dilakukan guna melihat beda selisih peningkatan fleksibilitas pada kedua Kelompok, didapatkan nilai $p$ yaitu 0,000 menunjukkan ada perbedaan bermakna, persentase peningkatan 7,791\% pada Kelompok I dan 17,061\% pada Kelompok 2 sehingga disimpulkan kelompok dengan kombinasi Foam Roller dapat meningkatkan fleksibilitas otot Hamstring lebih tinggi daripada kelompok tanpa kombinasi pada pemain sepak bola di FK Unud.
\end{abstract}

Kata Kunci : fleksibilitas, hamstring, contract relax stretching, foam roller

\title{
THE COMBINATION OF FOAM ROLLER AND CONTRACT RELAX STRETCHING IS BETTER ON INCREASING HAMSTRING FLEXIBILITY COMPARE THAN CONTRACT RELAX STRETCHING ON SOCCER PLAYER IN FACULTY OF MEDICINE UDAYANA UNIVERSITY
}

\begin{abstract}
Hamstring muscle flexibility is an important component because it can minimize the risk of injury to football players considering the case of high Hamstring injuries occurred in the game of football. This study proves the combination of Foam Roller and Contract Relax Stretching is better than giving Contract Relax Stretching alone in improving Hamstring muscle flexibility in soccer players. Prospective Method Pre-Post Test Design is used in this research. Each group amounted to 11 people by Simple Random Sampling in April-May 2018 at Physiotherapy Laboratory FK Unud. The result of Paired T-Test Group I obtained $p$ value $=0.000$ and Group II value $p=0,000$ so that the increase of Hamstring flexibility is very significant in each group. Independent T-Test to see difference difference of flexibility increase in both Groups, got $p$ value $=0,000$ which mean there is significant difference between both groups with percentage of increase 7,791\% in Group I and 17,061\% in Group 2 so concluded combination of Foam Roller and Contract Relax Stretching better than Contract Relax Stretching alone to increase Hamstring muscle flexibility in football players at FK Unud.
\end{abstract}

Keywords: flexibility, hamstring, contract relax stretching, foam roller 


\section{PENDAHULUAN}

Fleksibilitas merupakan hal yang sangat diperlukan pada permainan sepak bola. Pemain sepak bola perlu kondisi fisik yang bagus untuk menunjang kualitas permainannya. Pada atlet kasus cedera otot Hamstring terbilang tinggi yaitu sebesar $12 \% .{ }^{4}$ Peranan otot Hamstring terbilang cukup penting, khususnya pada pemain sepak bola yang banyak menggunakan tungkai pada permainannya. Kurangnya kemampuan fleksibilitas pada otot Hamstring menjadi salah satu sebab terjadinya cedera. Aktivitas yang terus-menerus pada pemain sepak bola menyebabkan kontraksi secara konsentrik dan eksentrik pada otot Hamstring sehingga pada saat gerakan cepat dan terjadi peregangan yang signifikan serta tidak diikuti dengan fleksibilitas otot hamstring yang baik, maka peluang terjadinya cedera akan lebih besar. $^{5}$

Kemampuan fleksibilitas yang baik diperlukan untuk dapat mengurangi risiko cedera tersebut, maka penting untuk menjaga fleksibilitas tetap baik, khususnya fleksibilitas otot Hamstring melihat besarnya persentase kejadian cedera pada Hamstring. Mempertahankan kemampuan fleksibilitas agar tetap baik diperlukan latihan untuk menjaga fleksibilitas, salah satu cara untuk menjaga fleksibilitas yaitu dengan stretching, ini merupakan istilah dari latihan otot dengan cara mengulur otot. ${ }^{6}$ Banyak metode penguluran atau stretching yang ada, salah satunya metode PNF (Proprioceptive Neuromuscular Fascilitation). Metode ini merupakan teknik penguluran atau stretching yang mampu meningkatkan fleksibilitas otot yang bekerja dengan cara memfasilitasi sistem neuromuscular dan merangsang

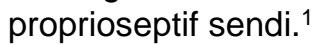

Contract relax stretching merupakan salah satu teknik PNF yang efektif dalam meningkatkan lingkup gerak sendi. Langkah pemberiannya yaitu kontraksi isometrik dengan tahanan berlawanan terhadap otot yang berkontraksi dilanjutkan dengan relaksasi kemudian dilakukan penguluran. ${ }^{8}$ Metode penguluran dapat dikombinasikan untuk mendapat fleksibilitas yang lebih baik, metode Self Myofasial Release adalah salah satu teknik yang dapat dikombinasikan dan terbilang mudah diterapkan karena dapat dilakukan secara mandiri. Teknik ini dapat dilakukan menggunakan Foam Roller yang dikatakan dapat meningkatkan lingkup gerak sendi dan memulihkan otot dengan cara mengurangi efek dari nyeri otot akut. ${ }^{9}$

\section{METODE}

Eksperimental prospektif pre-post test design adalah metode pada penelitian ini. Sampel ditentukan melaui kriteria inklusi yang tergabung pada pemain sepak bola Fakultas Kedokteran Universitas Udayana dengan IMT normal dan berusia 18-23 tahun, kemudian simple random sampling digunakan dalam pengambilan sampel. Besar sampel sebanyak 22 orang yang ditentukan menggunakan rumus Pocock. Sampel dibagi menjadi dua kelompok, tiap kelompok berjumlah 11 orang. Pembagian kelompok dilakukan dengan cara random alokasi. Kelompok 1 akan menerima latihan Contract Relax Stretching dan Kelompok 2 akan menerima latihan Contract Relax Stretching dengan kombinasi Foam Roller.

Sit and Reach Test adalah metode pengukuran yang digunakan untuk mengetahui tingkat fleksibilitas otot Hamstring pada penelitian ini. Alat ini berupa kotak pengujian dengan kotak padat setinggi $30 \mathrm{~cm}$. Penggaris di atas kotak, kemudian di posisikan sehingga $26 \mathrm{~cm}$ penggaris melewati tepi depan kotak ke arah subjek yang akan diukur. Tanda $26 \mathrm{~cm}$ harus berada tepat di tepi kotak. ${ }^{11}$ posisi sampel duduk dengan lutut lurus ke depan serta telapak kaki menempel pada kotak, kemudian sampel meluruskan kedua tangan ke depan sejauh kemampuan. Pengukuran dilakukan sehari sebelum perlakuan dan sehari setelah perlakuan terakhir.

Pemberian intervensi Contract Relax Stretching Kelompok 1 peserta diminta tidur terlentang, kemudian diintruksikan fleksi hip $70^{\circ}$, mengkontraksikan otot Hamstring secara isometrik selama 6 detik, kemudian relaksasi selama 3 detik dan dilanjutkan mengulur otot hamstring selama 20 detik. Dilakukan sebanyak 3 set dengan istirahat 20 detik antar set. ${ }^{13}$

Intervensi pada kelompok 2 yaitu kombinasi Foam Roller dan Contract Relax Stretching. Intervensi Foam Roller diberikan terlebih dahulu. Latihan dilakukan selama 40 detik dengan menggulingkan Foam Roller pada area otot Hamstring ulangi sebanyak 3 set. ${ }^{14}$ Setiap set istirahat selama 20 detik. Peserta beristirahat selama 2 menit kemudian dilanjutkan pemberian Contract Relax Stretching dengan prosedur sama seperti Kelompok 1. Intervensi pada kedua Kelompok dilakukan sebanyak 3 kali per minggu selama 4 minggu.

Perolehan data usia dan IMT dilakukan analisis deskriptif. Shapiro Wilk Test digunakan sebagai uji normalitas data dan Levene's Test sebagai uji homogenitas. Paired Sample T-test sebagai olah data beda pada tiap kelompok dan Independent Sample T-test untuk olah data beda antara kelompok.

HASIL

Pemain sepak bola Fakultas Kedokteran Universitas Udayana yang menjadi sampel yaitu sebanyak 22 orang dan tidak terdapat sampel yang dropout. Berikut tabel hasil olah data penelitian.

Tabel 1. Karakteristik Sampel Berdasarkan Data Usia dan IMT

\begin{tabular}{ccc}
\hline \multirow{2}{*}{ Karakteristik } & Klp I & Klp II \\
\cline { 2 - 3 } & Rerata \pm SB & Rerata \pm SB \\
\hline Usia (tahun) & $19,636 \pm 1,12$ & $20,818 \pm 1,25$ \\
IMT $\left(\mathrm{kg} / \mathrm{m}^{2}\right)$ & $21,373 \pm 1,17$ & $22,116 \pm 0,57$ \\
\hline
\end{tabular}


Tabel 2. Hasil Uji Normalitas

\begin{tabular}{ccccc}
\hline \multirow{3}{*}{ Kelompok Data } & \multicolumn{3}{c}{ Shapiro Wilk Test } \\
\cline { 2 - 5 } & \multicolumn{2}{c}{ Kelompok 1 } & \multicolumn{2}{c}{ Kelompok 2 } \\
\cline { 2 - 5 } & Rerata & $\mathbf{p}$ & Rerata & p \\
\hline Pre & 34,409 & 0,584 & 30,636 & 0,565 \\
Post & 37,090 & 0,704 & 35,863 & 0,200 \\
Selisih & 2,681 & 0,315 & 5,227 & 0,105 \\
\hline
\end{tabular}

Nilai $p>0,05$ berarti pada hasil uji normalitas dapat dilihat seluruh data berdistribusi normal, maka uji hipotesis yang digunakan yaitu statistik parametrik.

Tabel 3. Hasil Uji Homogenitas

\begin{tabular}{cccc}
\hline \multirow{2}{*}{ Kelompok Data } & Kel 1 & Kel 2 & Levene's Test \\
\cline { 2 - 4 } & Rerata & Rerata & Nilai p \\
\hline Pre & 34,409 & 30,636 & 0,038 \\
\hline Post & 37,090 & 35,863 & 0,022 \\
\hline Selisih & 2,681 & 5,227 & 0,793 \\
\hline
\end{tabular}

Hasil uji homogenitas didapatkan $p<0,05$ pada pre dan post yaitu data tidak homogen. Data selisih $p>0,05$ berarti homogen.

Tabel 4. Rerata Fleksibilitas Sebelum dan Sesudah Perlakuan Kelompok 1 dan Kelompok 2

\begin{tabular}{cccc}
\hline \multirow{2}{*}{ Data } & Pre & Post & Nilai \\
\cline { 2 - 4 } & Rerata \pm SB & Rerata \pm SB & p \\
\hline \multirow{2}{*}{ Klp 1 } & 34,409 & 37,090 & 0,000 \\
& $\pm 9,475$ & $\pm 8,711$ & \\
\hline \multirow{2}{*}{ Klp 2 } & 30,636 & 35,863 & 0,000 \\
& $\pm 4,884$ & $\pm 4,347$ &
\end{tabular}

Hasil $p<0,05$ menunjukan terdapat peningkatan Fleksibilitas yang signifikan sebelum dan sesudah perlakuan pada masing-masing kelompok.

Tabel 5. Uji Beda Fleksibilitas Sebelum, Setelah dan Selisih Perlakuan Antara Kedua Kelompok

\begin{tabular}{cccc}
\hline \multirow{2}{*}{ Data } & Klp 1 & Klp 2 & Nilai \\
\cline { 2 - 4 } & Rerata $\mathbf{S B}$ & Rerata $\mathbf{S B}$ & $\mathbf{p}$ \\
\hline \multirow{2}{*}{ Pre } & 34,409 & 30,636 & 0,259 \\
& $\pm 9,475$ & $\pm 4,884$ & \\
\hline \multirow{2}{*}{ Post } & 37,090 & 35,863 & 0,682 \\
& $\pm 8,711$ & $\pm 4,347$ & \\
\hline \multirow{2}{*}{ Selisih } & 2,681 & 5,227 & \multirow{2}{*}{0,000} \\
& $\pm 1,078$ & $\pm 1,126$ & \\
\hline
\end{tabular}

Hasil $p<0,05$ pada selisih perlakuan diartikan bahwa ada perbedaan peningkatan fleksibilitas yang bermakna antara kedua kelompok.

Tabel 6. Rerata Selisih dan Presentase Peningkatan Fleksibilitas pada Pemain Sepak Bola

\begin{tabular}{ccccc}
\hline Data & \multicolumn{4}{c}{ Hasil analisis } \\
\hline & Pre & Post & Seli-sih & Persen-tase \\
\hline Klp 1 & 34,409 & 37,090 & 2,681 & $7,791 \%$ \\
\hline Klp 2 & 30,636 & 35,863 & 5,227 & $17,061 \%$ \\
\hline
\end{tabular}

Persentase peningkatan fleksibilitas didapatkan pada Kelompok 1 yaitu 7,791\% dan Kelompok 2 sebesar 17,061\%. Hal ini memperlihatkan peningkatan yang terjadi pada Kelompok 1 lebih sedikit daripada Kelompok 2 yang berarti Kombinasi Foam Roller dan Contract Relax Stretching lebih baik daripada Contract Relax Stretching saja

\section{DISKUSI}

\section{Karakteristik Sampel}

Tabel 1. menunjukkan rerata umur sampel pada Kelompok 1 dan Kelompok 2. Hasil rerata usia pada tabel tersebut tergolong dalam kategori remaja akhir sehingga kemampuan fleksibilitas belum dipengaruhi oleh penurunan kemampuan jaringan lunak dimana semakin bertambahnya usia akan berpengaruh terhadap fleksibilitas yang diakibatkan oleh penurunan kemampuan jaringan lunak untuk memperbaiki diri. ${ }^{10}$

Rerata IMT yang tertera pada Tabel I menggambarkan sample pada kedua kelompok masuk pada kategori IMT normal yaitu18,5-22,9 kg/m². Kadar lemak yang tinggi cenderung memiliki fleksibilitas lebih rendah. ${ }^{7}$ Pengaruh tersebut dapat diminimalisir karena sample memiliki IMT normal.

\section{Contract Relax Stretching Dapat Meningkatkan Fleksibilitas Otot Hamstring Pada Pemain Sepak Bola}

Tabel 4. Kelompok 1 mendapat nilai $p<0,05$ menunjukan bahwa perlakuan Contract Relax Stretching pada Kelompok 1 dapat meningkatkan fleksibilitas otot Hamstring pada pemain sepak bola di Fakultas Kedokteran Universitas Udayana. Contract Relax Stretching dilakukan untuk mendapatkan efek relaksasi dan pengembalian panjang dari otot dan jaringan ikat. ${ }^{12}$ 
Perlakuan Contract Relax Stretching mengaktifkan golgi tendon organ yang merupakan komponen yang peka terhadap overstretch. Impuls afferent distimulasi menuju spinal cord, kemudian bertemu dengan hambatan motor neuron menyebabkan impuls afferent yang mengatur kontraksi terhenti oleh karena itu kontraksi otot menurun. Pemanjangan otot menjadi lebih mudah karena efek ini. Perlakuan ini terjadi pada aktin dan miosin, dengan dilakukan kontraksi dalan jangka waktu tertentu maka menimbulkan efek relaksasi yang memungkinkan otot lebih mudah untuk diulur. $^{1}$

Pemberian intervensi ini diperlukan adaptasi neurologi agar mendapat efek penengkatan kelenturan otot secara menetap. Latihan ini meningkatkan koordinasi intermuskular antar grup otot dalam waktu dua minggu jika dilakukan secara rutin. Peningkatan fleksibilitas baru akan terjadi pada jangka waktu latihan rutin selama empat minggu. ${ }^{3}$

\section{Kombinasi Foam Roller dan Contract Relax Stretching Dapat Meningkatkan Fleksibilitas Otot Hamstring Pada Pemain Sepak Bola}

Nilai $p<0,05$ yang diperoleh dari Kelompok 2 pada Tabel 4. menunjukkan bahwa terdapat perbedaan yang bermakna pada tingkat fleksibilitas otot Hamstring sebelum dan sesudah pemberian perlakuan, ini berarti kombinasi Foam Roller dan Contract Relax Stretching dapat meningkatkan fleksibilitas otot Hamstring pada pemain sepak bola di Fakultas Kedokteran Universitas Udayana.

Contract Relax Stretching merupakan salah satu metode yang terbukti dapat meningkatkan fleksibilitas Hamstring seperti pada pembahasan diatas. Pada Kelompok 2 metode Contract Relax Stretching dikombinasikan dengan Foam Roller. Hasil peningkatan fleksibilitas otot Hamstring dengan metode kombinasi ini menunjukkan perbedaan yang signifikan dibanding Kelompok 1 yang hanya diberi metode Contract Relax Stretching, sehingga dengan kata lain Foam Roller memberikan pengaruh yang cukup besar dalam peningkatan fleksibilitas otot Hamstring, sebagaimana dikemukakan bahwa Foam Roller merupakan salah satu alat untuk meningkatkan fleksibilitas Hamstring. ${ }^{2}$

Peningkatan fleksibilitas Hamstring dengan menggunakan metode Foam Roller memiliki beberapa mekanisme yang menyebabkan terjadinya peningkatan fleksibilitas. Fasia terdiri dari serat kolagen (baik tingkat yang rendah, serat elastis dan retikuler), fibroblas, dan jaringan dasar pengikat air. Fascia yang kehilangan fleksibilitas dan terbatas dapat menjadi faktor penyebab trauma, inflamasi atau imobilitas. Jaringan ikat yang keras dapat menyebabkan adhesi pada jaringan tersebut. Tujuan metode myofascial release adalah untuk merehidrasi fasia dan dengan cara ini membuat lingkungan ekstraselular mirip gel seperti cairan untuk menghasilkan peningkatan lingkup gerak sendi yang lebih besar. Penelitian sebelumnya menyatakan bahwa metode SMR (self myofascial release) dengan menggunakan Foam Roller menyebabkan kekakuan arterial akut berkurang dan fungsi vaskular endotel yang membaik. Melancarkan aliran darah merupakan tujuan lain daripada pemberian teknik myofascial release dengan menggunakan Foam Roller karena distensibilitas arteri dikaitkan dengan fleksibilitas. Mekanisme ini cenderung menjelaskan efek Foam Rolling dalam penelitian ini. Aspek kunci dari hilangnya fleksibilitas adalah keterbatasan fasia dan adhesi. Keterbatasan fasia dan adhesi menimbulkan kekakuan yang dapat menyebabkan tidak hanya masalah lokal tapi juga keseluruhan masalah pada tubuh dengan ketidakseimbangan akut dan kronis (ketidakseimbangan myofascial, disfungsi sendi, nyeri, dan disfungsi dalam sistem vena dan limfatik). Diasumsikan bahwa teknik SMR dengan Foam Roller memperbaiki konsekuensi ini. Penelitian sebelumnya menyatakan bahwa terdapat perbedaan yang signifikan dari matriks kolagen sebelum dan sesudah pemberian Foam Roller. Hal ini disebabkan oleh perubahan gaya mekanik fibroblas dan peningkatan mikrosirkulasi. Gaya yang dihasilkan saat menggunakan Foam Roller merangsang produksi kolagenase enzim yang bertanggung jawab untuk merombak matriks ekstraselular oleh fibroblas, oleh karena itu berdasarkan hasil penelitian sebelumnya berspekulasi bahwa ada efek jangka panjang positif dari teknik menggunakan Foam Roller pada keterbatasan dan adhesi fasia. Mekanisme tersebut membuat penggunaan Foam Roller dapat meningkatkan fleksibilitas seseorang. ${ }^{2}$

\section{Kombinasi Contract Relax Stretching dan Foam Roller Lebih Baik Dalam Meningkatkan Fleksibilitas Otot Hamstring Daripada Contract Relax Stretching Saja pada Pemain Sepak Bola}

Adanya perbedaan rerata selisih yang signifikan antara kedua kelompok pada Tabel $\mathrm{V}$ dan Persentase Peningkatan Fleksibilitas pada Tabel VI menunjukkan peningkatan sebesar $7,791 \%$ pada Kelompok 1 dan $17,061 \%$ pada Kelompok 2 yang berarti terdapat perbedaan yang signifikan antara Kelompok 1 dan Kelompok 2 . Hal ini berarti Kelompok 2 (Kombinasi Contract Relax Stretching Dan Foam Roller) lebih baik dibanding dengan Kelompok 1 (Contract Relax Stretching).

Hasil yang lebih baik pada Kelompok 2 untuk meningkatkan fleksibilitas otot Hamstring dapat disebabkan karena kedua kelompok perlakuan diberi perlakuan yang sama, namun pada Kelompok 2 ditambahkan dengan metode Foam Roller yang berpengaruh juga terhadap peningkatan fleksibilitas. Hasil ini didukung oleh Penelitian sebelumnya yang menyatakan bahwa kelompok dengan penambahan Foam Roller mendapat hasil yang lebih baik dibanding dengan kelompok perlakuan tanpa metode Foam Roller.

Peningkatan fleksibilitas yang lebih besar pada kombinasi Contract Relax Stretching dan Foam Roller dibandingkan dengan Contract Relax Stretching saja kemungkinan karena peningkatan suhu. Gerakan konstan pada prosedur metode Foam Roller sebelum perlakuan Contract Relax Stretching meningkatkan suhu jaringan intramuskular dan aliran darah, yang keduanya dikatakan meningkatkan sifat viskoelastik otot. Penjelasan lain yang mungkin adalah properti thixotropic di otot dan fasia. Dikatakan bahwa perubahan sifat thixotropic otot dan fascia menurunkan viskositas jaringan. Thixotropic adalah sifat dari beberapa gel atau cairan yang biasanya tebal (kental), tetapi tipis ketika mereka ditekankan. Dalam tubuh manusia, cairan sinovial yang melumasi sebagian besar sendi adalah thixotropic, seperti juga "substansi dasar" gelatin, yang merupakan bagian dari semua jaringan ikat seperti tendon dan ligamen. Thixotropic adalah salah satu alasan mengapa otot kita sedikit mengendur saat kita bergerak, sama seperti pemanasan oli mesin. 
Akibatnya, kekakuan pada jaringan menurun ketika Contract Relax Stretching diterapkan, sehingga menghasilkan ROM yang lebih besar. ${ }^{3}$

\section{SIMPULAN}

Penelitian ini mendapatkan kesimpulan bahwa kedua intervensi dapat meningkatkan fleksibilitas otot Hamstring namun Kombinasi Foam Roller dan Contract Relax Stretching lebih baik dibandingkan dengan Contract Relax Stretching saja pada pemain sepak bola di Fakultas Kedokteran Universitas Udayana.

\section{DAFTAR PUSTAKA}

1. Kisner, C. and Colby, L.A. 2007. Therapeutic Exercise Foundations and Technique. Fifth Edition. 5th edn. USA: F.A.Davis Company Laksosno, I.B. . Usulan Rancangan Perbaikan Meja dan Kursi Beajar Siswa SLTP Ditinjau dari Aspek Ergonomi. Universitas Sebelas Maret Surakarta. 2010

2. Junker, Daniel H. and Stoggl, T. L. 2015. The Foam Roll As A Tool To Improve Hamstring Flexibility. Journal of Strength and Conditioning Research. Volume 29(12), pp. 3480-3485.

3. Mohr, Long and Goad. 2014. Effect of Foam Rolling and Static Stretching on Passive Hip-Flexion Range of Motion. Journal of Sport Rehabilitation. Human Kinetics.

4. Ekstrand, J, Jeremiah C Healy, Markus Waldén, Justin C Lee, Bryan English and Martin Hägglund. 2012. Hamstring Muscle Injuries In Professional Football : The Correlation Of MRI Findings With Return To Play. Linköping University Post Print. British Journal of Sports Medicine. Volume 46, pp. 112-117.

5. Tsur, A. 2015. Hamstring Strain In Soccer Players: Things The Trainer Must Know. Journal of Exercise, Sports \& Orthopedics. Volume 2(2), pp. 1-4

6. Wiguna, P. D. A., Muliarta, I. M., Wibawa, A., Adiputra, L. M. I. S. H. 2016. Intervensi Contract Relax Stretching Direct Lebih Baik Dalam Meningkatkan Fleksibilitas Otot Hamstring Dibandingkan Dengan Intervensi Contract Relax Stretching Indirect Pada Mahasiswa Program Studi Fisioterapi Fakultas Kedokteran Universitas Udayana. Majalah Ilmiah Fisioterapi Indonesia. Volume 2(1), pp. 40-44.

7. Purnama, A. 2007. Hubungan Antara Indeks Massa Tubuh Dengan Fleksibilitas Lumbal. Fakultas Kedokteran Universitas Diponegoro.

8. Hindle, K. B., Tyler J. Whitcomb , Wyatt O. Briggs, Junggi Hong. 2012. Proprioceptive Neuromuscular Facilitation ( PNF ): Its Mechanisms And Effects On Range Of Motion And Muscular Function. Journal of Human Kinetics. Volume 31, pp. 105-113.

9. Cheatham, S. W. 2015. Systematic Review The Effects Of Self-Myofascial Release Using A Foam Roll Or Roller Massager On Joint Range Of Motion, Muscle Recovery, And Performance. The International Journal of Sports Physical Therapy. Volume 10(6), pp. 827-838.

10. Ibrahim, R. C., Polli, H., Wongouw, H. 2015. Pengaruh Latihan Peregangan Terhadap Fleksibilitas Lansia. Jurnal e-Biomedik (eBm), Volume 3 Nomor 1.

11. Quinn, E. 2016. Sports Medicine. [Online] About.com Available at: https://www.verywell.com/sit-and-reachflexibility-test-3120279 [diakses 6 Januari 2018].

12. Wismanto. 2011. Pelatihan Metode Active Isolated Stetching Lebih Efektif Daripada Contract Relax Stretching Dalam Meningkatkan Fleksibilitas Otot Hamstring. Jurnal Fisioterapi. Volume 11(1), pp. 77-92.

13. Riebe D., Ehrman, J. K., Liguori, G., Magal, M. 2016. Guideline for Exercise Testing and Prescription. ACSM (American College of Sports Medicine) Tenth Edition

14. Mohr, A. R. 2015. Effectiveness Of Foam Rolling In Combination With A Static Stretching Protocol Of The Hamstrings. Oklahoma State University 